\title{
The Artistry of Language in Piano Teaching
}

\author{
Gaoyang Liu \\ Sichuan University of Arts and Science \\ Dazhou, China 635000
}

\begin{abstract}
In recent years, with the rapid development of the piano, pianists have conducted a series of in-depth and thorough discussions on piano teaching models, teaching methods, performance techniques, and achieved substantive progress. However, there is still a lack of in-depth research on improving classroom art and the artistic language of instruction. Especially the abuse and misuse of language in piano teaching has become an urgent problem to be solved. The paper begins with the important role of language in piano teaching. By analyzing the typical problems in piano teaching language today, it proposes that its teaching language should be professional, accurate, refined, logical, and visualized.
\end{abstract}

Keywords—piano teaching; language; artistic

\section{INTRODUCTION}

With the popularity and maturity of the piano, China has gradually become the world's piano power. Piano training schools and piano art centers are springing up everywhere followed by that piano teachers are increasing. In the actual piano teaching, teachers often only pay attention to the guidance of performance techniques as well as the analysis of the works, and the examination and comment on the completion of the students' work, but they ignore the artistic use of language in teaching, which not only makes the classroom boring, tedious and lacks infectious power, but also wastes class time, misleads students' self-evaluation, obscures students' understanding of knowledge, further seriously affecting teaching effectiveness. Changing this status quo and letting the piano teaching language become artistic can not only improve the quality of teaching, but also have a very important meaning in teaching of words and deeds and the two-way process.

\section{The Role of LANGUage In PiAno TeACHING}

\section{A. Language Is the Transmission Belt for Knowledge and Skills}

The transmission belt is mainly used to convey objects in industrial production, and its characteristics are convenient, efficient, and regular. In piano teaching, the language also has the same meaning. Since the birth of piano teaching, language has always played a role in transmission, even in the current information age. However, the use of traditional languages has been at the core of the teaching process and will not disappear. The piano is a comprehensive skill course integrating music theory, solfeggio, harmony, and musical form. In the classroom teaching, whether the teacher is explaining the basic knowledge of music, or analyzing the works, as well as the exploring performance skills, it is inseparable from the transmission of language. So, language is the transmission belt of knowledge and skills in piano teaching.

\section{B. Language Is the Bridge of Communication between Teachers and Students}

Bridges are different from transmission belts and their difference lies in communication and interaction. With the implementation of the student-centered and teacher-led education orientation by the Ministry of Education, students' initiative, creativity, and communicability have greatly improved. Even in the children's piano teaching, there often happens that student put up questions actively and discuss jointly. At this time, the use of language becomes more important. It not only expresses the ideas and opinions of teachers and students most directly and quickly, but also generates new ideas and viewpoints through the mutual intersection and collision of the two parties' information, and combines real-time practice, so that the desired teaching effect can be got. In piano teaching, whether it is a piano major or a piano common lesson; an enlarged piano lesson or a smaller piano lesson, teacher-student interaction is the guarantee of teaching effectiveness and it is the key to finding problems, researching problems, and solving problems. Among these, language plays a role as a bridge. It is both a growing place for professional knowledge and a stage for the exchange of the mind.

\section{Language Is the Indicator Light}

In addition to the functions of transmission belts and bridges, the language of piano teaching has the function of indicator lights. As the piano lessons are very operative and skillful, the "master teaches apprentice" has always been a unique form of teaching in piano teaching. Teachers must make clear and specific instructions based on each student's different levels of professionalism, different ability to accept, comprehension, and personality traits, and its qualities are both different from conveying and instilling. It is an instruction made by teachers through combining knowledge, skills, information, analysis and other factors with their teaching experience and accurate evaluation. It is not only a guide to students' learning direction, but also a hint for students' playing skills as well as a solution to students' puzzlement and confusion; it not only embodies the characteristics of piano teaching, but also reflects its important directive role laterally. 


\section{The Problem of Language Use IN Piano Teaching}

\section{A. The Abusive Use of Casual Words}

Casual words are not equal to spoken words. Spoken language refers to the language form that is different from written expression in order to increase the comprehensibility and popularity of the language. It is often simple and clear, with regional and affinity characteristics; casual words mean words that are spoken out without thinking or careful thinking.

Its main performances are: the first is to freely praise and encourage students. When the quality of the students' return classes is obviously poor, and even when there are serious problems, some teachers will still casually say some words of mouth out of habits, such as "playing really well", "behaving very well" , and "more progress" and so on. In particular, some teachers in training institutions, in order to retain students, always praise students, even without any reason. Over time, it will not only seriously affect the student' $s$ learning outcomes, but will also develop students' bad habits that they can only hear the sound of singing, but not tolerant criticism. It is undeniable that students should be encouraged mainly (especially children), but this must be based on a scientific and objective basis. It isn't advisable to praise and encourage them causally. The second is casual criticism for students. When students do not perform well in class, some teachers will habitually criticize: "play blindly", "too bad", "too stupid", "too stupid" and other spoken words without thought. Classroom is not only a place for teaching, but also a place for cultivating people. What the teacher says to students should not only have a strict scientific nature but also be an objective and impartial and caring, which not only means a respect for knowledge but also a correct judgment and impetus for students. So whether it is to praise or critique the students, it must be well-founded and scientifically objective. All language from the teachers' mouth should afford to be considered and examined.

\section{B. Fuzzy Positioning}

The vagueness of language positioning in piano teaching is also a major issue, which is mainly reflected in the analysis of the techniques and works of piano performance and the assignment of work. First, it refers to the vagueness of speed. For example, the works of the Baroque period, the Classical period, and the Romanticism period are generalized; the etudes, polyphony, sonatas, and music standards are conflated. Teachers do not pay attention to the different styles of different periods, the specific requirements of different works, and the actual needs of music. They just replace all the Allegro by using "fast", "still fast", "faster" and other languages .In contrary, the word of "slow", "still slow", "slower" tend to be used to instead of all the adagio, so that there is no accurate positioning. Whether it is the Allegretto or Allegro and whether it is a very strict Adagio or a relatively free Adagio; whether it is 125 beats or 130 beats per minute, many teachers do not have accurate positioning. The second is the fuzziness of strength and weakness: the control of strength in piano playing is of vital importance and even the key to victory. In the course of teaching, many teachers do not attach importance to their special training, so that they just talk about briefly and fuzz the arrangement up in the teaching, which leads the students to lack of the ability of weak control and lack of a sense of hierarchy in playing. For example, they play Bach's polyphony and Liszt's Rhapsody to the same intensity; require Beethoven's f with the same standard as Mozart's f as well as Debussy's pp with Scarlatti's pp, regardless of the time of the works, and even simply requiring students in the aspects of strength, not to mention that accurately express the multi-level progression of pppp to ffff. The third one refers to vague analysis of the internal structure of music and the image of music. In addition, they fail to accurately express musical, music chapters, music phrases, music period, and music movement, so that they are not able to describe the image of the work in a proper way. The fourth is that the teacher cannot pierce the heart of the matter, and the layout of the homework is general.

\section{Lack of Appeal}

Infective language teaching can not only make the class lively and interesting, but also can motivate students' enthusiasm and attract students' attention, resulting in a significant increase in teaching effectiveness. In reality teaching, many teachers do not pay attention to improving the appeal of their language, mainly in: the first is that their sounds are too small in class. Because the piano lessons are classified into enlarged classes, group lessons, small lessons, professional lessons, and common piano lessons, it is difficult to satisfy students' hearing with the same volume; the second is that there is no reasoning in the language expression and no sense of hierarchy; the third is that language does not have a sense of rhythm or strength, but uses only one tone, one frequency, and one intensity, so that people listen to it tediously, making it difficult to find their meanings and points; the fourth is that the key difficulties are not prominent. "What I say goes" and "cramming education" have become a way for many teachers to attend class. The emphasis and difficulty are not only reflected in lesson plans, but more often in classroom teaching; the fifth, the lack of expressive power is mainly reflected in: the expression is cumbersome, evasive, inadvertent, inadequate in linguistic standards, muttered and even prattled.

\section{The ART of LANGUAgE In Piano TEACHING}

\section{A. Specialization}

The specialization of piano teaching language is not only suitable for piano professional courses, but also for all piano lessons. In reality teaching, some teachers do not pay attention to this problem, mainly in ignoring the use of musical terminology, especially the use of unique terminology of piano. For example, they refer to the piano works as "a certain song" (especially piano music adapted by the vocal works), call the break a "jump", call the rhythm as a beat, call the speed term as the expression term, call" playing the piano" as "smashing the piano", etc. The professional use of piano teaching language is the key to piano teaching. It can not only improve classroom efficiency, but also improve classroom quality. In the course of teaching, the teachers should grasp the following aspects: the first is the professional expression of the terms of 
music: rhythms, rhythms, continuous, broken, and non continuous plays; monosyllabic, falling, three tone, and slippery lines; falling arm, walking, running, and raising wrist should be used standard. Second, it is necessary to accurately express the language related to the internal development and structure of music. In the piano classroom teaching, the structure of the multi - sound, multi - level and multi - line structure makes the teachers should more clear and specialized in the use of language in teaching. Third, the language interpretation of playing skills should be specialized. Piano playing is inseparable from the basic elements of strength, speed, and height. In piano teaching, it is important to use the unique professional language of the piano. For example, the explanation of force should be: natural fall, support, transmission, relaxation, wrist raising and so on; the expression of the high and low tone area should be: small groups, how many small word groups, how many big word groups several groups, how may line to add in upper part (lower part) to locate; the expression of sound should be natural, bright, concentrated, hazy, clear and broken; the explanation for the footboard should be: homophonic footboard, connecting footboard, weak footboard, middle footboard, dithering footboard (broken footboard) and so on.

\section{B. Precision}

The precise use of the piano teaching language can make the students more thorough in knowledge understanding, more directed to the skill of playing, and more pertinent to the problem solving. It is not only reflected in the use of professional terms in teaching, but also embodied in the thinking, mentality and language organization in the whole teaching process. For example, in the process of student performance, ff (strong) cannot be expressed as extra strong, and the third measure starts from $\mathrm{p}$ ascending to sixth measure $\mathrm{f}$, then the fourth measure should be positioned $\mathrm{mp}$, and the fifth measure is mf, not just say "here is getting stronger"; when describing the structure of Chopin's "B b minor nocturne Op.91 ", it should be said that the song structure of the work is to reproduce the single trilogy (AB-A'), paragraph A section 18 (1-18), paragraph B section 51 (19-69), section A'16 (70$85)$.On the contrary, they should not simply use the colloquial expression of "this paragraph", "this section" and "these sentences"; similarly, in the guidance of students' performance skills, they should also pay attention to the expression of language accuracy. For example, "bulleting," "fast," "pop," "stretch," "pop-up" "play with affection," and other fuzzified languages should be described exactly:"playing with f," "Playing with 130 beats per minute," "Playing with legato".

\section{Refining}

The use of language in piano teaching should also focus on refinement, which can save time in classroom teaching and allow people to have enough space for thinking. The refined language is mainly manifested in: the first is to use written language rather than oral language. Every sentence should be considered as a language that helps to accomplish teaching objectives and contents. Second, in addition to the important and difficult points, the rest of contents need to avoid repetition and unnecessary details. The third is not to use the customary mantra. Many teachers like to add "this" and "that" before each sentence and add the phrase "is it right?" at the end of the sentence, which not only does not play any role, but makes language impractical and incompetent. Only a refined language will make people sound clean and effective, offer people with enough room for thinking, and have the emphasis and difficulties.

\section{Logicalization}

The logic of language can make the classroom more hierarchical and rational. It is first manifested in the logic of thinking, In the process of teaching, teachers must have clear minds and ideas, and know how to ask questions, analyze problems and solve problems; how to go from the shallow to the deep, from the form to the inside; teachers should be confident in their minds. The second is the logic of language. In the process of teaching, teachers should not only grasp the logical relationship between the time and space of language, but also have the overall layout that is closely linked the front part and the back part. In class, teachers should avoid jumping in thinking, language disorder, and vague levels. Only by achieving a high degree of unity of thinking and language, can teaching achieve a multiplier effect.

\section{E. Visualization}

The visualization of language in piano teaching can make the classroom more vivid and interesting and easy to understand. Meanwhile, it helps to make abstract musical notes concrete and boring sounds fun. For example, Wang Jianzhong's piano song "Hundred Birds and Phoenix" includes cuckoos, doves, swallows, yellow tits, thrushes, owls and other bird sounds. Teachers should imitate the voices of these birds as much as possible in class to reproduce the images and scenes of the works; at the beginning of the first movement of Beethoven's Piano Sonata "Sorrowfulness", the use of expressions such as "dialogue between heaven and hell, confrontation between movement and silence, and contradiction between reality and idealism" can better enhance students' understanding of the author' $s$ heart. In this piano piece, "river, mountains, sea, ice, and sunset" are used to describe the scene in the music; "Emperor, ministers, people, and beggars" are used to describe different characters in the music of the works; the words of "beautiful, kind, ugly and evil" show different psychology and "houses, beams, bricks, doors and windows" are used to describe the structure of the works. Drawing from what we see and making metaphors according to things around us will make the music more concrete and interesting, so as to make class teaching effectively.

\section{CONCLUSION}

Piano teaching cannot be separated from the use of language. The use of language cannot be confined to simple transmission and communication, but also to the art of language. Only by using the art of language, such as specialization, precision, refinement, logic and visualization, can the quality of classroom teaching be improved effectively. At the same time, it is conducive to promoting and improving teachers' teaching level, sublimating their classroom teaching 
art, and playing the role of teaching by words and example, teaching benefits teachers as well as students.

\section{REFERENCES}

[1] Jing Leng. On Language Art in Piano Teaching[J].Journal of Suzhou University of Science and Technology(Social Science Edition),2008(03): 135-137. 冷静.谈钢琴教学中的语言艺术[J].苏州 科技大学学报(社会科学版),2008(03): 135-137

[2] Rui Li. Bichun Situ.Language Art of Piano Teaching[J].Piano Art,1998 (05 ):35-36. 李荵.司徒璧春.钢琴教学的语言艺术[J].钢琴艺术,1998 (05):35-36

[3] Bo Zhang.A Preliminary Study on the Language Art of Piano Teachers[J].Art Education, 2010(04):43. 张波.钢琴教师语言艺术初探 [J].艺术教育, 2010(04):43

[4] Yili Liu, Sha Li. On Language Skills in Piano Teaching[J]. Yellow River of the Song, 2008( 11):68-89. 刘毅力.李莎论钢琴教学的语言技 巧[J].黄河之声, 2008( 11):68-89

[5] Rong Peng. Teacher's Language Use in Children's Piano Teaching[J].The Sea of Art, 2012 (09)：157-158. 彭荣.儿童钢琴教 学中的教师语言运用[J].艺海, 2012（09）：157-158 